\title{
The Finger and Palmer Dermatoglyphics among the Various Caste Groups of North 24 Parganas, West Bengal, India
}

\author{
Debankana Bandyopadhyay* \\ Former guest researcher, Anthropological survey of India, India
}

Received: February 24, 2018; Published: March 12, 2018

*Corresponding author: Debankana Bandyopadhyay, Former guest researcher, Anthropological survey of India, India, Email: debankana25142008@gmail.com

\begin{abstract}
The present study aims at determining the variation in Dermatoglyphics patterns in both sexes (male, female), of three different caste group (Brahmin, Kayastha, Namasudra) of Birati area. There are 300 individuals are considered as a subject of this specific study and their two parameters are used that is the differences between the ridge pattern of the fingertip and the Pattern Intensity Index (PII) variation in case of both sexes that is male and female and in between three caste groups that is the Brahmins, the Kayasthas, and the Namasudras. Inferential statistics are used to justify the data and check the data is significant or not. The PAST software is used to analysis the data. The results suggest that the variation in the ridge pattern of male and female is clearly showed and there are vast variation is found in between the three caste groups (Brahmin, Kayastha, Namasudra).
\end{abstract}

Keywords: Dermatoglyphics; Arch; Whorl; Radial Loop; Ulnar Loop Pattern Intensity Index (PII)

\section{Introduction}

Dermatoglyphics was derived from the Greek word "dermis" meaning "skin" and the "glyph" meaning "curving". Dermatoglyphics is a term first coined by Cummings and Milado [1]. Dermatoglyphics is the scientific study of papillary ridges in the palm of the hand and soles of feet Purkinje. The first classification of finger prints (digital pattern) into Arch, Loop and Whorl was done by Sir Francis Galton (1892). Although the arrangements of skin ridges never duplicated in two persons even in monozygotic twins, the similarities are closer among some individuals while in others the differences are marked. It is the study skin ridges which are found on the finger pad, palm, and toes and soles it includes anthropologic genetic and Egypt logic study of finger print. Fingers have dermal ridge configuration having grooves in between them. They developed at 13th week of prenatal life and remain unchanged throughout the remaining life, thus providing marks of individuality. Finger print is a multifactorial trait. Large number of genes plays their role along with environmental influence [2]. Actually there is large number of genes determining the ridge pattern. Chromosomal aberrations affect these genes and produce variations in Dermatoglyphics pattern in various chromosomal syndromes. Average frequency of different epidermal ridge patterns such as whorl, ulner loop, radial loop, and arch in whole world population is $25 \%, 70 \%,<1 \%$ and $5 \%$ respectively.

\section{Materials and Methods}

The study data forms were prepared for taking finger prints.300 individuals were randomly selected for the present study among which both males and females that is both sexes are studied and the individuals are from three different caste groups that is Brahmin, Kayastha and Namasudra. Among the individuals 100 individuals(male-50,female-50) are from Brahmin group, 100 individuals(male-50,female)belongs to kayastha community and 100 individuals (male-50,female-50) from namasudra caste group. It is a cross sectional descriptive study under taken using quantitative method [3]. Classical ink -pad method and paper method was used for its simplicity and convenience. Each digital pad of both hands was pressed against inked cotton pad. Then it was rolled in specific box on data form. By this method, sharp and clear fingerprint were obtained. The fingerprints were studied with the help of magnifying glass (Figures 1-3). 


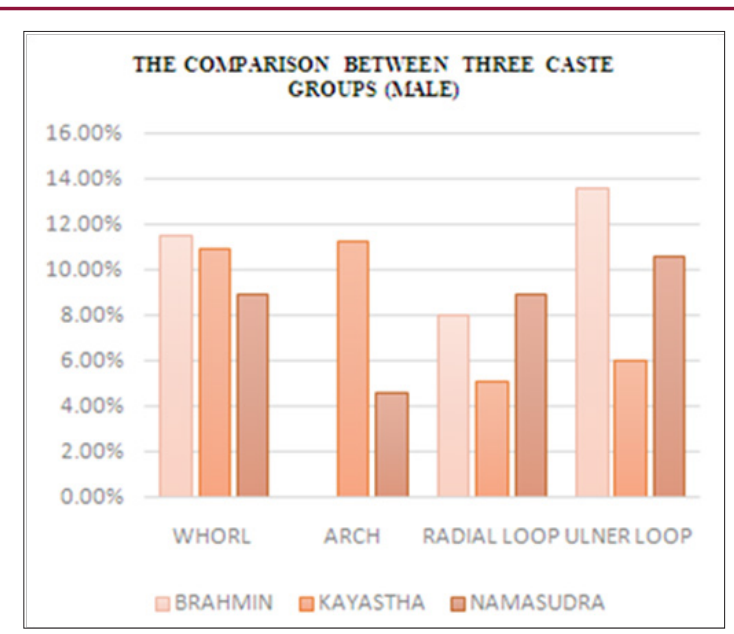

Figure 1: The Brahmins has highest frequency in ulner loop that is $13.64 \%$ the percentage of whorl, arch, radial loops are $11.52 \%, 0.06 \%, 8.01 \%$ respectively. In case of kayasthas the arch have highest percentage that is $11.32 \%$ and the other ridge pattern such as whorl, radial loop, ulner loop have $10.92 \%, 5.16 \%, 6.09 \%$ respectively. In case of namasudra community the ulner loop has highest percentage that is $10.66 \%$ and the percentage of whorl arch and radial loop are $9.00 \%, 4.63 \%$ and $8.94 \%$ respectively.

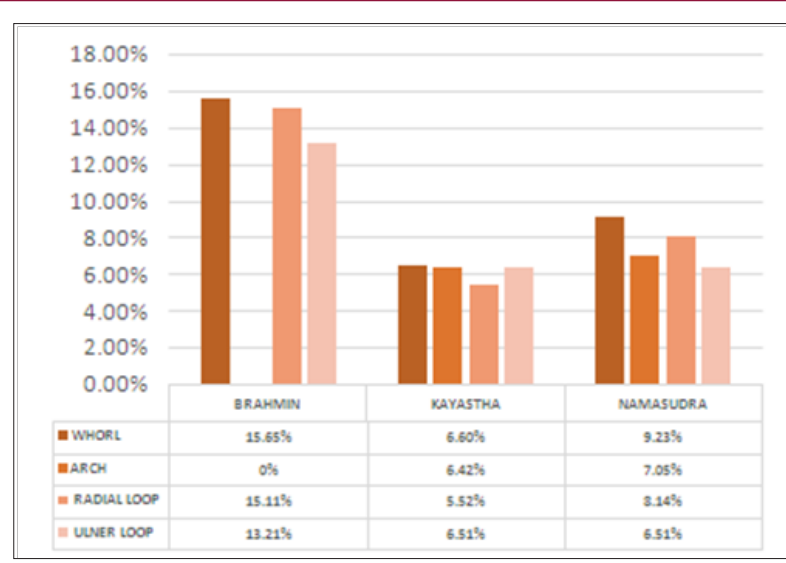

Figure 2: the Brahmins has highest frequency in whorl that is $15.65 \%$ the percentage of ulner loop ,arch, radial loops are $13.21 \%, 0 \%, 15.11 \%$ respectively. in case of kayasthas the whorl have highest percentage that is $6.60 \%$ and the other ridge pattern such as arch, radial loop, ulner loop have $6.42 \%, 5.52 \%, 6.51 \%$ respectively. In case of namasudra community the whorl has highest percentage that is $9.23 \%$ and the percentage of arch and radial loop, ulner loop are $7.05 \%, 8.14 \%$ and $6.51 \%$ respectively.

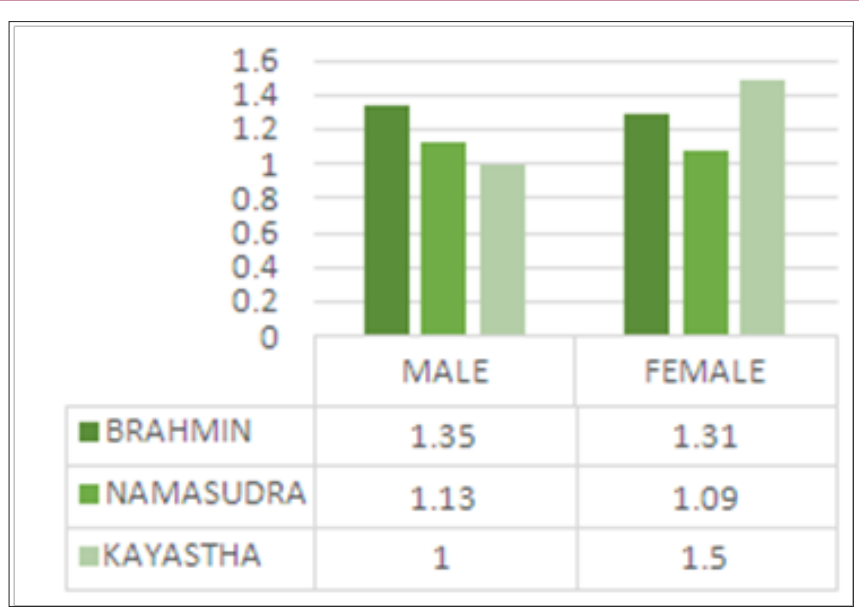

Figure 3: Comparison between male and female of Brahmin, Namasudra, Kayastha population in case of Pattern Intensity Index (PII). 


\section{Statistical Analysis}

The PII and the numbers of the ridge pattern that is whorl, arch, and radial, ulner loop were calculated. The significance of differences between the observed parameter was evaluated by student" $t$ " test and chi-square test.

\section{Results and Discussion}

The analysis showed that in case of male population. The Brahmins has highest frequency in ulner loop that is $13.64 \%$ the percentage of whorl, arch, radial loops are $11.52 \%, 0.06 \%$, $8.01 \%$ respectively [4-6]. In case of kayasthas the arch have highest percentage that is $11.32 \%$ and the other ridge pattern such as whorl, radial loop, ulner loop have 10.92\%, 5.16\%,6.09\% respectively. In case of namasudra community the ulner loop has highest percentage that is $10.66 \%$ and the percentage of whorl arch and radial loop are $9.00 \%, 4.63 \%$ and $8.94 \%$ respectively. The analysis showed that in case of female population. The Brahmins has highest frequency in whorl that is $15.65 \%$ the percentage of ulner loop, arch, radial loops are $13.21 \%, 0 \%, 15.11 \%$ respectively. In case of kayasthas the whorl have highest percentage that is $6.60 \%$ and the other ridge pattern such as arch, radial loop, ulner loop have $6.42 \%, 5.52 \%, 6.51 \%$ respectively. In case of namasudra community the whorl has highest percentage that is $9.23 \%$ and the percentage of arch and radial loop, ulner loop are $7.05 \%, 8.14 \%$ and $6.51 \%$ respectively.

The analysis showed that in case of pattern of pattern intensity index the males of Brahmin population have greater frequency. In this Brahmin female population has greater frequency in comparison of other females of kayastha and Namasudra population. The females of kayastha population showing the greatest frequency in case of pattern intensity index that is 1.5 .The Namasudra female shows lesser number of presence of the index. That is 1.09 and kayastha population shows the lesser number of frequencies in case of pattern intensity index.

\section{Conclusion}

The analysis showed that there is a large variation is found in three population Brahmin, Kayastha, Namasudra population in case of the ridge pattern of fingertip that is ulner loop is frequently found in Brahmin population where it is rare in Namasudra population like this all of three caste groups showed noticeable variation between the two groups and also between the male and female belongs to same caste group of my studied population.

\section{References}

1. Cummins H, Midlo C (1943) Finger Prints, Palms and Soles-An introduction to dermatoglyphics. The Blakiston Company, Philadelphia, US, p. 11.

2. Biswas S (2011) Finger and Palmar Dermatoglyphic Study among the Dhimals of North Bengal, India.

3. Ashbaugh RD (1999) the history of friction ridge identification. In: Quantitative-qualitativefriction ridge analysis- an introduction to basic and advanced ridgeology. CRC Press publisher, New York, USA.

4. Bleehen SS, Ebling FG (1988) Disorders of skin colour. In Text book of dermatology (Eds.). A Rook, DS Wilkinson, F.1.G. Ebling and RH Champion.

5. Sumit kar, Ajay krishna, Abihijit b, Atul D (2012) Digito-Palmar Dermatoglyphics in Vitiligo. A case-control Study. Journal of the Saudi Society of Dermatology \& Dermatologic Surgery16(2): 61-66.

6. Poch GA, Smith DW (1970) the genesis and significance of digital palmer hand creases Preliminary report. J Pediats 77: 1017-1023.
CC (i) This work is licensed under Creative Submission Link: https://biomedres.us/submit-manuscript.php

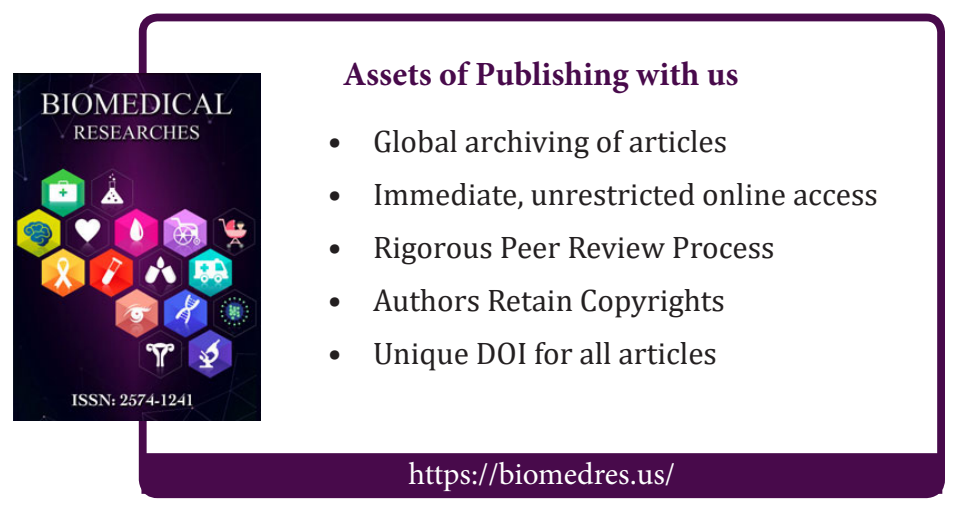

